\section{APUNTES PARA UN ESTUDIO COMPARATIVO ENTRE TORCIDAS ORGANIZADAS E HINCHADAS}

\author{
NOTES FOR A COMPARATIVE STUDY BETWEEN SUPPORTER GROUPS \\ FROM BRAZIL (TORCIDAS ORGANIZADAS) AND ARGENTINA (HINCHADAS)
}

\author{
APONTAMENTOS PARA UM ESTUDO COMPARATIVO ENTRE TORCIDAS \\ ORGANIZADAS EHINCHADAS
}

Marcelo Fadori Soares Palhares ${ }^{*}$, Nicolas Cabrera**, Gisele Maria Schwartz ${ }^{* \star *}$
Keywords

Football.

Sociology.

Recreational

activities.

Palavras-chave

Futebol.

Sociologia.

Atividades de lazer.
Abstract: The present study proposes an initial approach to a comparative study between supporter groups from Brazil (torcidas organizadas) and Argentina (hinchadas). The text presents a thick description that points to similarities and differences, in synchronic and diachronic terms, between both groups of football spectators. The paper focuses on each group's emergence, organizational framings, logics of belonging, and most significant practices and representations. Finally, it illustrates the contributions of this research to the construction of a public sociology of regional sport.

Resumo: No presente estudo se propõe uma primeira aproximação comparativa entre torcidas organizadas e hinchadas. 0 texto apresenta uma descrição densa que aponta semelhanças e diferenças, em termos sincrônicos e diacrônicos, entre ambos grupamentos de espectadores de futebol. Se focalizará os contextos de surgimento, os enquadramentos organizacionais, as lógicas de pertencimento e as práticas e representações mais significativas de cada um dos objetos empíricos analisados. Finalmente explicitaremos alguns aportes para a construção de uma sociologia pública do esporte regional.
* Programa de pós-graduação em Ciências da Motricidade.Universidade Estadual de São Paulo (UNESP). Campus Rio Claro. Rio Claro, SP. Brasil. E-mail: marcelofsp@ @otmail.com

** Pós-grado en Universidad Nacional de Córdoba (UNC). Córdoba, Argentina. E-mail: nico_cab@ hotmail.com

*** Departamento de Educação Fisica da UNESP. Campus Rio Claro. Rio Claro, SP. Brasil. E-mail: schwartz@ rc.unesp.br

Recebido em: 18-06-2014 Aprovado em: 18-10-2014

\section{(c) (i) () Licence}




\section{INTRODUCCIÓN}

América Latina parece tener dos columnas vertebrales: una geográfica conocida como "la cordillera de los Andes"; y otra deportiva, el fútbol. Convertido en uno de los rituales más masivos de nuestras sociedades contemporáneas, este deporte representa una metáfora y una metonimia privilegiada para poner en práctica nuestras ciencias sociales. Desde los pioneros Eduardo Archetti (1985) y Roberto Da Matta (1979) sabemos que no se trata de hacer "[...] sociología del fútbol, sino hacer desde el fútbol sociología". Entre la multiplicidad de aristas en las que podemos desagregar el "campo futbolístico", en los últimos años parece ser un tópico recurrente -principalmente desde los medios de comunicación masivos- el de la violencia protagonizada por dos tipos de espectadores organizados vinculados al fútbol: las hinchadas argentinas y las torcidas organizadas brasileras. Sin embargo, creemos que la visibilidad del fenómeno no se tradujo en explicaciones pertinentes.

En el sentido anteriormente señalado, el presente artículo representa una primera aproximación al estudio comparativo entre la hinchada argentina del Club Atlético Belgrano de Córdoba autodenominada "Los Piratas" y la torcida organizada del São Paulo FC autorreferenciada como "Dragões da Real"1. El trabajo buscará presentar una "descripción densa" (GEERTZ, 1990) en clave cotejada a los fines de trazar continuidades y diferencias, diacrónicas y sincrónicas, entre los universos internos de estos dos tipos de colectivos de espectadores que encuentran en el fútbol un espacio de referencia común, pero que se configuran a partir de procesos locales disímiles.

En la primera parte del texto nos limitaremos a contextualizar y precisar de manera breve lo que entendemos por hinchadas y torcidas organizadas a los fines de circunscribir nuestros objetos de estudio; en un segundo apartado se reconstruirá en clave diacrónica los orígenes de las hinchadas y torcidas organizadas en general y de nuestros referentes empíricos en particular; el tercer apartado consiste en una descripción densa comparativa de las lógicas internas que configuran los colectivos en cuestión. Finalmente se esbozaran algunos comentarios finales sobre la relevancia, los desafíos y las limitaciones que presentan los trabajos de esta naturaleza.

\section{DE AGUANTES Y BUROCRACIAS}

Ni las "hinchadas" en Argentina, ni las torcidas organizadas en Brasil representan las únicas formas de organizaciones de espectadores de un determinado club. Según Toledo (1996) en el fútbol brasilero coexisten dos formas distintas de organización de las asociaciones de hinchas: las torcidas uniformizadas y las torcidas organizadas, sin embargo sobre tal diferenciación es necesaria una mirada más atenta: La Torcida Uniformizada do São Paulo (TUSP), originada en 1940 y la Charanga Rubro-Negra do Flamengo, originada en 1942, son citadas en diversos estudios académicos sobre torcidas organizadas como las primeras organizaciones colectivas que buscaban alentar a un equipo de fútbol. Estos colectivos tenían un vestuario específico (remera del equipo, que en aquella época era poco frecuente), utilizaban instrumentos musicales y tenían un jefe, que generalmente tenía ciertas vinculaciones con

1 La elección de dichos referentes empíricos se debe principalmente a dos razones: la primera es que ambos casos constituyen los objetos de estudio de nuestras respectivas investigaciones de posgrado; y lo segundo es que por sus dimensiones, lógicas internas y contextos de inscripción, nos parecen dos casos que con sus similitudes y diferencias se prestan para un análisis comparativo pertinente. Cabe señalar que en ambos casos el trabajo de campo consistió en observaciones participantes y entrevistas semiestructuradas mediante una estadía prolongada y sistemática en el campo, focalizando en las prácticas y representaciones de los miembros de la hinchada y la torcida organizada. 
el club (TOLEDO, 1996, 2002; PIMENTA, 1997; SANTOS, 2004; MURAD, 2007; HOLANDA, 2009; CANALE, 2012; PALHARES et al., 2012).

A pesar de ser caracterizadas como las primeras organizaciones de torcedores con el objetivo de alentar un equipo de fútbol, la TUSP y la Charanga, no pueden ser consideradas torcidas organizadas, ni uniformizadas. El vínculo directo con el club, la presencia de "torcedores-símbolos", la identificación restricta al club y principalmente el rechazo al uso de la violencia, son factores que sirven para diferenciar las primeras organizaciones de hinchas de los movimientos actuales. En líneas generales podemos decir que para diferenciar entre organizada y uniformizada se debe tener en cuenta la organización del grupo en cuestión. En este sentido, los estudios de Holanda (2009) y Canale (2012) pueden auxiliar en esta diferenciación, que no es solamente de términos o vocablos, sino también conceptual y teórica. Veremos que cada concepto se refiere a un tipo de organización específica. Así como señalan los dos autores, en la década de 40, ya existían grupos con la denominación "torcida organizada"2, pero estos no podrían ser considerados como tales, debido a su organización, estructura y prácticas.

Con base en esto, de modo general, se puede decir que las torcidas uniformizadas se constituyen como grupos que se encuentran para apoyar sus respectivos equipos, todos utilizando la misma ropa pero no constituyendo una institución. En cambio las torcidas organizadas son una institución jurídica, reconocida por ley (con encuadramiento funcional de gremio recreativo). En resumen, la principal diferencia entre los dos grupos, torcida uniformizada $x$ organizada, seria la cuestión burocrática-legal presente en las torcidas organizadas ya que son instituciones reconocidas por la ley.

La estructura organizativa más general, pero no absoluta, de las torcidas organizadas es la elección de formulas para ocupar la función de "diretoria". Sin embargo, cabe señalar que cada torcida organizada puede decidir sus propias formas de organización acerca de su organigrama interno. Con esto se puede decir que las torcidas organizadas poseen una organización burocrática propia (TOLEDO, 1996; PIMENTA, 1997).

Para el caso argentino también resulta fundamental la diferenciación de dos tipos de hinchas organizados que se identifican fuertemente con un club: los hinchas militantes y las hinchadas o barras ${ }^{3}$ (ALABARCES, 2004). Los primeros generalmente se nuclean en espacios institucionales del club como las sub-comisión del socio o en filiales regionales. Los segundos tienen una estructura organizativa informal desde el punto de vista institucional pero claramente vertical y jerárquica.

Ambos grupos comparten la característica de identificarse a partir de la noción nativa de aguante, pero mientras que para los primeros dicho concepto aparece asociado al aliento y la fidelidad incondicional por el equipo; para los segundos el aguante está asociado a un universo moral donde se valora positivamente la violencia física. En resumen, ambos grupos de hinchas están bastante organizados, pero los "militantes" lo hacen dentro de un marco formalinstitucional y las "hinchadas" desde la informalidad.

\footnotetext{
2 Algunas torcidas cariocas sirven como ejemplo: "Torcida Organizada do Fluminense" de 1939, "Torcida Organizada do Vasco" de 1944 "Torcida Organizada do Bangü" de 1952 y la "Torcida Organizada do Botafogo" de 1957, aunque tenían en el nombre el término "organizada", por su estructura, organización y practicas no podrían ser encuadradas como torcida organizada (HOLANDA, 2009). Estos grupos anteriormente comentados se asemejaban más a lo que hoy conocemos como torcidas uniformizadas. De la misma manera, actualmente, existen grupos que son denominados "uniformizados" pero se constituyen como una torcida organizada, como por ejemplo la Torcida Uniformizada do Palmeiras (TUP). Por lo tanto, la forma de organización del grupo determina como éste debe ser caracterizado.

3 "hinchadas" y "barras" son las categorías nativas con las que se identifican los propios miembros de estas organizaciones. Aquí utilizaremos
} dichas nociones en reemplazo del mote mediático y estigmatizador de "barras bravas" 


\section{CONTEXTO DE SURGIMIENTO: COMPARACIÓN EN CLAVE DIACRÓNICA}

El movimiento de las torcidas organizadas empezó entre fines de 1960 y principio de los años 70. Como anticipamos anteriormente, no hay consenso sobre la primera torcida organizada de Brasil. Algunos estudios académicos (TOLEDO, 1996; PIMENTA, 1997) apuntan a "Gaviões da Fiel" y la "Torcida Jovem del club Santos Futebol Clube" como las primeras torcidas organizadas, ya que se fundan, respectivamente, en los meses de julio y septiembre de 1969. Sin embargo, otros datos empíricos y académicos refutarían esta afirmación de Toledo (1996) y Pimenta (1997) ya que la Torcida Jovem do Flamengo alega haber sido fundada en 1967 producto de una ruptura de la Charanga Rubro-Negra, pues algunos integrantes cuestionaban tanto las formas de gerenciamiento de la torcida (relaciones de amistad entre miembros del gobierno y policía) y a su jefe ${ }^{4}$ (HOLANDA, 2009). Ya en el ámbito de los estudios académicos, el estudio de Canale (2012) apunta que el origen de la Torcida Jovem da Ponte Preta ocurrió en marzo de $1969^{5}$.

A pesar de la discusión sobre cual realmente fue la primera torcida organizada, lo que sí queda claro es que el surgimiento de estas organizaciones ocurrió en el contexto de la dictadura militar en Brasil ${ }^{6}$. En aquella época gran parte de la sociedad civil no tenía mucha participación política en las estructuras tradicionales, sin embargo, y en paralelo, sí se noto un aumento en el involucramiento e interés por la esfera deportiva.

Un ejemplo de dicho aumento en la participación fue el nacimiento de la torcida Gaviões da Fiel que surgió como una forma de protesta al presidente del club y su gestión política. Los hinchas de Corinthians deseaban mayor participación política en el club y querían tornarlo más democrático. Además de eso el equipo no obtenía buenos resultados deportivos, hecho que aumentaba la presión hacia los dirigentes (TOLEDO, 1996; HOLANDA, 2009).

El motivo de aparición de las torcidas organizadas en Brasil fue el interés en participar más activamente de las decisiones del club, en medio de un período donde los canales tradicionales de participación estaban cerrados (PIMENTA, 1997). En ese contexto y bajo una similar tendencia fue que se dio la fundación del "Grêmio Recreativo Torcida Organizada Dragões da Real'. Esta es una de las torcidas organizadas del club São Paulo Futebol Clube y se autodenomina "Dragões da Real". La misma resultó del añadimiento y la unión de otras pequeñas torcidas en el período de 1979 y 1984.

Dragões da Real fue el nombre con el que se autodenominó la torcida del club São Paulo, pues proviene de la mezcla de nombres de dos torcidas que se unieron: "Dragões do Mais Querido" y "Real Força Inflamante Tricolor". La elección de la palabra "Dragões" fue debido al carácter místico de dicho animal y al alto número de asociados de la torcida que tenían origen oriental. Además de eso, los dragones, según los miembros, tienen estricta relación con la cultura oriental. Ya el nombre "Real" fue mantenido de la torcida "Real Força Inflamante Tricolor".

4 Este cuestionamiento generó la salida de muchos miembros de la Charanga y culminó en la creación del movimiento Torcidas Jovens, hecho ocurrido principalmente durante los años 70 . Éste movimiento desencadenó el añadimiento de pequeñas torcidas con las emergentes Torcidas Jovens.

5 De acuerdo con Canale (2012) existen dos factores que pueden explicar la constante referencia a Gaviões da Fiel como la primera torcida organizada. El primer motivo es que la Torcida Jovem da Ponte Preta se organizaba de manera semejante a las torcidas uniformizadas paulistas (como la anteriormente referida TUSP). Siendo así, se puede decir que la Torcida Jovem da Ponte era una torcida uniformizada cuando fue fundada. El segundo motivo es la historia y representatividad de Gaviões da Fiel que por su convocatoria, repercusión y visibilidad es probable que haya eclipsado el anterior nacimiento de la Torcida Jovem da Ponte Preta.

6 La dictadura brasileña duró de 1964 hasta 1985. 
Por su parte, en la Argentina podemos decir que será entre fines de la década del 50 y durante todo los 60 la época en la que las "hinchadas" pululen (ROMERO, 1986). Si bien hasta la fecha escasean los estudios sobre el tema, hay algunos indicios para animarse a pensar que el nacimiento de las "barras" responde a dos condiciones estructurales del período histórico mencionado anteriormente: en la Argentina predominaba una cultura política dominada por el autoritarismo, la violencia organizada e institucionalizada, la acción colectiva, la proscripción y la ilegalidad, fundamentalmente por una clausura para vastos sectores de la sociedad civil de las vías institucionales- legales democráticas (CAVAROZZI, 2006) y un progresivo incremente de la violencia política. Y por el otro lado, en el campo específico del fútbol, se registraba una creciente mercantilización a partir de la "modernización" (ROMERO, 1986) exitosa del deporte. Los recursos circulantes se incrementan, la disputa por ellos también.

En ese contexto surge la barra del Club Atlético Belgrano de Córdoba en 1968 y se autodenomina Los Piratas. Sobre el mote de "Los Piratas" hay varias versiones contrapuestas pero en casi todas aparece un elemento recursivo: el carácter "pirata" sería un derivado de una práctica generalizada entre los miembros de la hinchada que consistía en saquear y robar pertenencias ajenas, principalmente cuando la "barra" se trasladaba a diferentes estadios para acompañar al equipo.

Los Piratas también se arrogan hoy ser "la primera barra de Córdoba" debido a su prematuro nacimiento en relación a las otras hinchadas de Córdoba. La barra en sus comienzos aparece ligada al movimiento obrero peronista y sindicalizado, y con una fuerte pertenencia al barrio de Alberdi, lugar en el que se encuentra el actual estadio del club Belgrano.

Como primer punto histórico-comparativo podríamos pensar en torno a la siguiente hipótesis: tanto las torcidas organizadas y las hinchadas en general, como los Dragões da Real y Los Piratas en particular, son hijos de un contexto macro político represivo y excluyente en el que estas nacientes organizaciones se presentaban como espacios de fuga para "hacer política" y reunirse colectivamente frente a la clausura de los canales políticos- institucionales tradicionales. No es casual que el escenario propicio para ello haya sido el fútbol, ya que en ambos países dicho deporte representa una esfera pública, popular, masiva, cotidiana y estructural en el que los procesos identitarios y culturales poseen gran capacidad de producción y reproducción.

Además, por las características anteriormente mencionadas, se puede hipotetizar que el fútbol mostraba importantes barreras al control, la censura y la represión de los aparatos dictatoriales respectivos, lo cual no implica que ellos no hayan permeado y reconfigurado el ámbito futbolístico, pero probablemente se encontraron allí con mas resistencias e impugnaciones que en otros ámbitos de la sociedad civil.

\section{ESTRUCTURA, ORGANIZACIÓN Y LÓGICAS INTERNAS: COMPARACIÓN EN CLAVE SINCRÓNICA}

En términos generales, Pimenta (1997) plantea que el camino de organización interna adoptado por la mayoría de las torcidas organizadas ${ }^{7}$ fue la vía institucionalizada, convirtiendose así en una organización burocrática. Esto implica, por un lado reglas y jerarquías; y por el

7 Aún que la mayoría de las torcidas organizadas tengan esta organización burocrática propia, actualmente hay grupos que son contrarios al título y al modelo de organización de las torcidas organizadas. Los movimientos populares de torcidas en la ciudad del Rio de Janeiro, señalados por Teixeira (2013), así como los del Sur del país, en ciudades como Criciúma y Porto Alegre son ejemplos de eso. Incluso estos movimientos populares se asemejan a las hinchadas argentinas en algunos puntos como por ejemplo lo referido a la dimensión visual-estético. 
otro una rama de funciones, cargos y roles. Este tipo de organización burocrática crea la figura de un asociado de la torcida organizada.

El procedimiento inicial para tornarse un miembro asociado de Dragões da Real es llenar una planilla de inscripción con los datos personales y pagar un valor de inscripción (30 reales para hombres y 15 para mujeres). Aproximadamente a los 20 días el interesado recibe una tarjeta de asociado y pasa a ser considerado un torcedor organizado formalmente. Después de ser registrado en la torcida Dragões da Real, el torcedor aun necesita registrarse a la Federação Paulista de Futebol $\left(F^{2} F^{8}\right)$ para ingresar al estadio con la vestimenta de una torcida organizada.

No hay ninguna restricción explicita sobre las condiciones para participar en Dragões da Real. Hombres, mujeres y mayores de edad pueden participar por igual, incluso en las caravanas. Solamente los chicos menores de edad (menores de 18 años) necesitan de una autorización formal de los padres para tener la tarjeta de asociado. A pesar del número aun pequeño de mujeres, ellas están presentes en Dragões, e incluso pueden competir por los cargos de la junta directiva, pero actualmente no hay ninguna mujer en la diretoria.

Según Toledo (1996) el organigrama de una torcida organizada varía principalmente de acuerdo con: el número de asociados, el patrimonio y la ideología de la torcida en cuestión. Cabe señalar que la cuestión política puede cambiar el organigrama de una torcida organizada, pues la disputa por el poder puede generar grupos claramente opuestos.

La torcida Dragões da Real tiene 16 mil miembros asociados desde su fundación en el año de 1984. Este número de miembros corresponde a la base del registro histórico de la torcida. Esto significa que desde 1984, 16 mil personas se afiliaran a Dragões, lo cual no significa que hoy la torcida cuente con ese número de miembros activos, que actualmente es cerca de 200 personas. Estos son los torcedores que participan efectivamente en la cotidianeidad de la torcida (ir a la cancha, frecuentar la sede, ayudar con los preparativos y organización general). En el momento de ir a los estadios este número puede fluctuar según el equipo juegue de local o visitante, siendo para el primero caso aproximadamente 200 personas y 50 para el segundo.

Esquemáticamente la organización interna actual de Dragões da Real se puede dividir en cuatro grandes grupos que se estructuran jerárquicamente en términos de poder, pero más democráticamente en términos de derechos. El modelo piramidal es el más pertinente para explicar las asimetrías dentro de esta torcida ya que coexisten, por un lado, pocos miembros en posición de liderazgo, posesión del poder y toma de decisiones y, por el otro, muchos miembros en posición subalterna que no forman parte de las decisiones.

Cabe señalar que en relación a los derechos (principalmente de voto) Dragões se constituye como una organización democrática, pues todos los miembros con más de un año de asociado y que estén al día con el pago de la mensualidad pueden votar para elegir la diretoria. La posibilidad de que gran parte de los asociados puedan elegir la diretoria no está presente en muchas otras torcidas organizadas, principalmente en las más numerosas, pues hay un miedo de los directores de que personas nuevas puedan llegar al poder y modificar mucho la torcida (TOLEDO, 1996; PIMENTA, 1997).

8 El registro de todos los torcedores organizados en la FPF puede ser solicitado por las autoridades del gobierno y policía en caso de episodios de violencia. Por lo tanto, los torcedores organizados deben presentar su tarjeta de registrado juntamente a la FPF en el momento de entrada en el estadio. 
El primer grupo de Dragões está compuesto por los miembros de la actual diretoria, que contiene a 7 personas. La composición de este grupo ocurre básicamente en dos momentos distintos. El primero es la elección del presidente y del vicepresidente por los miembros de la torcida por medio de elecciones, que ocurren cada cuatro años. Después de elegidos, el presidente y su vice, empiezan a convocar personas de su confianza para formar la diretoria. A partir del consenso entre el presidente y el vice se crean los cargos dentro de una torcida. Esta situación puede generar la formación de una rama muy extensa de funciones y responsabilidades dentro de una torcida.

La diretoria de Dragões forma el núcleo duro de la torcida, pues contiene las personas que centralizan el poder y lideran la toma de decisiones. Este grupo tiene como responsabilidad gestionar de forma general la torcida y representa a una especie de junta directiva. Organiza las caravanas, elige diretore ${ }^{9}$ representa la torcida frente a los miembros del Estado, establece y mantiene relaciones con otras torcidas organizadas, tiene las entradas cedidas por el club ${ }^{10}$ para los partidos y organiza las sub sedes. La diretoria posee el poder y elige los rumbos de la torcida, es decir, este grupo es directamente responsable por la situación y las acciones de la torcida de una forma general.

El segundo grupo es el Conselho Permanente. Grupo constante, sin muchas modificaciones a lo largo de los años (mucho menos cambiante que la diretoria por ejemplo), compuesto por 10 personas, todos hombres adultos (entre 28 y 40 años) con mucha trayectoria 0 "conceito" en la torcida. Este grupo sirve para auxiliar a la actual diretoria, debido a que gozan de reputación y respeto por parte del resto de los miembros por su larga experiencia en la torcida. Este grupo está formado por ex presidentes, vices, miembros de conselhos y diretorias anteriores. Cada participante del Conselho elige su propio sustituto.

El Conselho puede auxiliar en caso de quejas, protestas y desaprobaciones hacia la actual diretoria, siempre tendiendo hacia una postura "neutra" y pensando "en lo mejor" para la torcida. Este grupo tiene un importante poder simbólico debido al reconocimiento y respeto del que gozan sus miembros, pero no cuenta con mecanismos de acción efectiva para orientar el rumbo de la torcida. Siendo así, la decisión siempre es de la diretoria.

El tercer grupo está compuesto por los miembros con más antigüedad en la torcida y que con mayor frecuencia asisten a los partidos y a la sede. Este grupo contiene muchos miembros responsables de tareas y funciones dentro la torcida como los que forman la bateria (conjunto de instrumentos musicales), los puxadores (que empiezan las canciones) y los responsables por bandeirões, faixas y bandeiras. Este tercer grupo es compuesto por 100 personas aproximadamente.

Por último, el cuarto grupo está compuesto por el resto de los miembros de la torcida organizada. De una forma general este grupo está formado por aquellos miembros de esporádica o muy escasa frecuencia en la cotidianeidad de Dragões. Por consecuencia, estos miembros tienen poco reconocimiento dentro de la organización, no suelen ser identificados como pares o directamente pueden ser desconocidos por los miembros de la torcida, pero aun así poseen la tarjeta de socio y los mismos derechos de todos los otros miembros de Dragões. Muchos

9 Personas responsables por la ejecución de las funciones fundamentales para la organización de la torcida, por ejemplo: cuidar de los instrumentos, comandar canciones, abrir y cerrar la sede, contabilidad y organizar fiestas).

10 Cabe señalar que actualmente debido a muchos factos de violencia protagonizados por las torcidas organizadas muchos clubs brasileños (por ejemplo Cruzeiro y São Paulo) dejaran de dar entradas gratuitas a los torcedores organizados. 
miembros de este grupo podrían ser llamados povão ${ }^{11}$ por los torcedores organizados que componen los tres grupos arriba citados ${ }^{12}$.

Al igual que la mayoría de las hinchadas argentinas, "Los Piratas" son una organización heterogénea y compleja. Su lógica interna y composición ha ido mutando en términos diacrónicos, ya que históricamente en ella han convivido distintos líderes o "referentes" como así también diversas facciones. Las divisiones internas han ido configurando un complejo organigrama mediado por relaciones de diferencias y desigualdades que permanentemente oscilan entre el consenso y el conflicto, dualidad que muchas veces desemboca en enfrentamientos violentos.

Desde los años 2010 y 2011 la hinchada de Belgrano entró en un período de disputas internas que terminó con la instalación de una hegemonía monopólica por parte de una de las facciones. El sector autodenominado "Los Piratas Celeste de Alberdi", comandados por un antiguo referente conocido como "Loco Beto"13, expulsó violentamente de la tribuna a las otras dos facciones identificadas como "la 19 de marzo" y "la banda del Jetón Marcos". Desde los acontecimientos citados anteriormente, la facción "Los piratas celestes de Alberdi" se erigió en la única que maneja la totalidad de la barra "Los Piratas" (CABRERA, 2013a).

Sin embargo, la hinchada del Club Atlético Belgrano no es una organización uniforme y monolítica ya que ella sigue subdividida en pequeños grupos de distintos barrios de la ciudad de Córdoba, cada uno de estos pequeños grupos tienen uno o varios referentes que están vinculados de alguna forma con el jefe máximo de la hinchada.

Esto demuestra que el organigrama de la hinchada es estrictamente vertical y jerárquico, tanto en relación a las interacciones entre los distintos sub grupos como a los roles, las funciones y los beneficios que le corresponden a cada miembro dentro de la barra. De todas formas cabe resaltar un dato crucial de la estructura interna de la hinchada: existe una autoridad unipersonal -el "loco Beto"- cuya dominación y legitimidad al interior de la hinchada es casi absoluta. Todas las decisiones logísticas, estéticas, políticas y económicas pasan por él.

La verticalidad del organigrama interno también se observa en una clara división del trabajo, hay roles y referentes asignados para las diversas actividades de la hinchada: transporte de "bombos", "banderas" y "telones", sus ubicaciones en la tribuna, organización de viajes, reventa de carnets ${ }^{14}$, invención de canciones, gestiones de algunas vestimentas propias de la barra, negociaciones con el resto de los actores futbolísticos (jugadores, dirigentes, policía, etc.) entre otros.

Actualmente la hinchada de Belgrano se encuentra en un proceso de crecimiento. A pesar de tener una cantidad muy fluctuante de miembros, podemos decir que su totalidad oscila entre los 200 y 300 integrantes aproximadamente, aunque existe un núcleo duro y fijo de no más de 80 personas. Todos ellos son hombres, las mujeres tienen vedada la pertenencia a la barra aunque muy pocas veces algunas de ellas puedan frecuentar los espacios de la hinchada

11 La palabra povão es utilizada por los organizados para denominar personas que no tienen vínculo con ninguna torcida organizada, pero simpatizan con estas instituciones. El povão se constituye como una otredad para los organizados, así como todos los torcedores comuns, hinchas sin ningún vínculo con las torcidas organizadas.

12 Cabe señalar también la formación de pequeños grupos que se autodenominan "bondes". Estos grupos se generan de forma espontanea, teniendo fuerte identificación regional o barrial ("Bonde da leste", "Bonde da norte", "Bonde do centro", "Bonde do ABC") que a veces se traduce en disputas físicas y simbólicas con otros bondes de otros equipos por el comando de una determinada región o barrio. El número y composición de estos bondes no es constante porque estos se generan de forma autónoma. Son subgrupos fluctuantes que se autogeneran, autogobiernan y son independientes del comando de la sede. En Dragões están en el tercer grupo (miembros más antiguos y frecuentes).

13 Los nombres y apodos reales de nuestros informantes han sido tergiversados a los fines de mantener su anonimato.

14 Los dirigentes de Belgrano les ceden a "Los Piratas" una importante cantidad de carnets para que ingresen gratuitamente sus miembros, el excedente de esos carnets se vende a "hinchas comunes" que no tienen entradas. 
(reunión previa al partido, centro de tribuna popular, viajes de visitante, etc.). Además de las mujeres, también se puede observar una fuerte segregación de los niños. Si bien se observan muchos infantes familiares de los miembros de la hinchada en los partidos, en las reuniones o en la tribuna popular cantando las canciones, ellos son excluidos explícitamente de muchas actividades de las barras como los viajes, algunas reuniones donde circula alcohol y drogas y los mismos enfrentamientos violentos.

Otra alteridad que se construye sistemáticamente al interior de la hinchada lo representa la noción nativa de "puto"15 en oposición a la de "macho". La dicotomía identitaria entre "machos"-"putos" pasa fundamentalmente por la predisposición o no para los enfrentamientos corporales violentos. Mientras que los "machos" tienen "huevos" porque se "la bancan", esto se expresaría en su valentía, coraje, fuerza física y propensión a la violencia; los "putos" no son "verdaderos hombres" ya que su "carencia de huevos" se expresaría principalmente en que rehúsan los enfrentamientos violentos, ellos "corren" en todos lados, no "se paran de manos" (CABRERA, 2013b). Lo anteriormente expuesto deja a las claras el lazo indisoluble que existe en el universo moral de la hinchada entre violencia y masculinidad (GARRIGA ZUCAL, 2005).

La gran mayoría de los miembros efectivos de la hinchada son hombres jóvenes y adultos, pertenecientes a una franja etaria que ronda entre los 15 y los 40 años de edad aproximadamente. En menor medida hay un porcentaje que van desde los 40 hasta los 60 años. Esquemáticamente podemos decir que hay tres grupos etarios diferenciados, que además implican roles y jerarquías claramente diferenciadas: los más jóvenes (entre 15 y 25 años) que generalmente componen la "música de la barra" (tocar "bombos" o los "vientos") o portan las banderas de mano, ellos ocupan el eslabón más bajo de la estructura piramidal; hay un segundo grupo de adultos (entre 25 y 40 años) que representan la población más numerosa y que combinan una mayor variedad de roles logísticos como: la distribución de las banderas en la tribuna, el traslado de los bienes simbólicos de la barra (bombos, banderas, "telones", etc), la arenga desde los para-avalancha y pueden contar con algún excedente de carnets para distribuir entre pares o comercializar; por último se encuentra un grupo menor en términos cuantitativos pero de gran peso cualitativo, nos referimos a los miembros mayores que van desde los 40 hasta los 60 años aproximadamente. Este último grupo es el circulo de mayor confianza del Loco Beto y de él dependen las decisiones fundamentales de la barra (distribución de recursos, inversiones, lazos políticos, amistades- enemistades con otras hinchadas, etc.)

Como se desprende de la descripción sistematizada anteriormente, podemos observar que entre "Los Piratas" y "Dragões" hay fuertes continuidades en lo que respecta a su organización interna. En ambos casos estamos frente a colectivos fuertemente organizados, con estructuras verticales y jerarquías bien delimitadas. También encontramos frecuentes disputas y conflictividades internas que se traducen en organigramas fluctuantes, no en su forma pero sí en su contenido. La estructura se mantiene, los nombres cambian. En ambas organizaciones existen asimetrías de poder que se expresan en lógicas diversas a la hora de tomar decisiones u orientar el rumbo del colectivo.

Existen también universos simbólicos de prestigio, reconocimiento y respeto entre los miembros que no solo marca jerarquías sino también delimitaciones identitarias que se expre-

15 La noción de "puto" al interior de la hinchada, está vinculada a prácticas sexuales, pero no se agota en esa dimensión. El "puto" no solo refiere a un rol u orientación sexual, sino también a una predisposición reticente, evasiva y pacifista frente a los enfrentamientos violentos, por lo que equiparar "puto" con homosexual es correcto pero reduccionista. En la categoría de "puto" no solo se instituye a los homosexuales como alteridad, sino también se confirma a las prácticas violentas —el aguante— como relaciones de poder y dominación. 
san en fronteras simbólicas y materiales que definen quienes formas parte de la organización y quiénes no. Además se registran instancias comunes que operan como esferas aglutinadoras de los miembros de ambos colectivos: el club como institución, el estadio como territorio, las reuniones propias como escenarios de interacción en espacios prefijados y los días de partido como ritual social. Por último podemos decir que la cantidad de miembros efectivos en ambos casos parece ser tan fluctuante como coincidente en términos cuantitativos.

Sin embargo, las diferencias entre ambos casos son tan visibles como complejas. La principal de ellas parece ser el régimen burocrático- legal en el que se inscribe "Dragões da Real" en comparación con la informalidad e ilegalidad en la que se mueven los "Los Piratas". Esta diferencia no solo se traduce en estructuras organizativas disimiles sino también en lógicas de funcionamiento sincrónicas y diacrónicas y en prácticas y representaciones que parecen tener poco en común. Lo primero para resaltar en este sentido es el fundamento de la autoridad máxima de la organización.

Siguiendo a Max Weber podemos decir que la legitimidad sobre la que se sostiene la cima de cada pirámide es diferente en cada uno de los casos empíricos analizados. En Dragões la dominación legitima de la diretoria parece descansar principalmente ${ }^{16}$ en criterios racionales-legales ya que su poder, esto es, "la probabilidad de imponer la propia voluntad, dentro de una relación social" (WEBER, 1994, p. 43), "descansa en la legalidad de ordenaciones estatuidas y de los derechos de mando de los llamados por esas ordenaciones a ejercer la autoridad" (WEBER, 1994, p. 172). La presencia de estatutos, la sujeción a la ley, las funciones y roles reglamentados formalmente, las burocracias y cuotas económicas periódicas y "blanqueadas", son todos elementos que nos llevan a pensar en una dominación principalmente legal y racional. Además estamos frente a una autoridad colegiada con decisiones vinculantes (diretoria) que puede auxiliarse en otro estamento de la misma naturaleza (Conselho Permanente)

Por su parte "Los Piratas" se estructuran en una autoridad unipersonal (El Loco Beto) que fundamenta su poder en una hibridez entre "dominación tradicional" y "dominación carismática" (WEBER, 1994, p. 172). "Beto" supera los 60 años de edad y conduce a la barra desde hace más de 30 años -y está como miembro de la hinchada desde los orígenes de la mismay permanentemente recurre mediante narrativas orales a los orígenes míticos del colectivo como fuente de legitimación. Él historiza una tradición realizando una simbiosis simbólica entre su trayectoria personal y los vaivenes de "Los Piratas"17. Su "experiencia" en el mundo de las hinchadas se deriva de su supervivencia como máxima autoridad desde "tiempos lejanos" (WEBER, 1994, p. 180) en un ambiente que es representado por los propios "Piratas" como hostil y violento.

Pero además de la tradición, en Los Piratas se construye una dominación de tipo carismática. Beto es objeto de prestigio, reconocimiento y respeto ya que en él se depositan rasgos de "heroísmo o ejemplaridad" (WEBER, 1994, p. 173). No alcanza con "ser un viejo referente" sino que durante esa trayectoria se tiene que haber demostrado con creces la posesión y acumulación del capital más preciado por Los Piratas: el aguante. Beto experimentó todos los enfrentamientos violentos que la hinchada protagonizó en sus últimas décadas, y en varias

16 Como se desprende también de la teoría weberiana, vale aclarar que en ninguno de los dos casos la dominación legitima recae exclusivamente en la mencionada, ya que estos tipos ideales nunca se expresan de forma "pura" en la realidad.

17 La identificación simbólica e histórica entre "Los Piratas" y "El Loco Beto" se ejemplifica en la nominación completa de la hinchada de Belgrano cuando se plasma en banderas, pintadas, remeras, canciones, etc. Su nombre completo aparece como "Los Piratas Celestes de Alberdi. La histórica barra del Loco Beto". 
de ellas -según como lo reconstruye la memoria colectiva de la hinchada- salió victorioso. Su cuerpo resistió literalmente más de 7 disparos de arma de fuego, eso en el universo moral de "Los Piratas" es una de las pruebas irrefutables de su corporalidad aguantadora.

Otra diferencia importante son los mecanismos y recursos disponibles a partir de los cuales se construye la membresía de cada colectivo. En Dragões la primera barrera está dada por trámites burocráticos (planilla de inscripción, tarjeta de asociado y registro en FPF) y no parece haber restricciones muy claras a la pertenencia, hombres y mujeres, adultos, jóvenes y hasta niños pueden gozar de dicha membresía. Nuevamente los limites identitarios de primer nivel (quienes forman parte y quienes no) responden a una lógica burocrática- legal.

Muy por el contrario, las lógicas de ingreso a los Piratas no están materializadas burocráticamente sino que responden a experiencias de tipo ordinarias y extraordinarias: en las primeras tenemos los rituales cotidianos propios de la hinchada como asistir a sus reuniones, cumplir un rol en la división del trabajo, ir al estadio y compartir escenarios de esparcimientos ajenos al mundo futbolístico con otros miembros de la hinchada; y están las experiencias extraordinarias donde emergen fundamentalmente los enfrentamientos violentos. Muchas veces demostrar "aguante" en alguno de esos casos puede ser sinónimo de un reconocimiento identitario al interior del grupo. Además la hinchada de Belgrano excluye de muchos rituales propios de la barra a mujeres y niños.

\section{REFLEXIONES FINALES}

Quisiéramos finalizar con algunos comentarios que se desprenden de lo anteriormente expuesto y que consideramos vitales en pos de construir una sociología pública del deporte para la región. En primer lugar nos parece central resaltar la pertinencia de abordar sociológicamente el deporte, ya que sigue siendo un campo privilegiado para comprender facetas, componentes, paradojas y contradicciones de una sociedad. $Y$ más aun con las particularidades que reviste el fútbol en las sociedades argentinas y brasileras.

En segundo lugar remarcamos la necesidad de incentivar co-producciones y diálogos académicos entre investigadores de diversos contextos. Exponer científicamente las continuidades y diferencias entre espectadores de fútbol a nivel local (hinchadas e hinchas militantes; torcidas organizadas y torcidas uniformizadas), a nivel regional (hinchadas y torcidas organizadas) y a escala global (incorporando a los ultras y hooligans por ejemplo) resulta imprescindible para construir trabajos académicos integrales, interdisciplinares y críticos.

Por último, está la imprescindible tarea de pensar políticas públicas en materia de seguridad para el campo futbolístico. El punto de partida para ello debe ser un cuadro de situación en el que se detallen las especificidades de cada contexto local y regional. Homologar y simplificar las lógicas de las hinchadas y las torcidas organizadas lleva a diagnósticos erróneos, y éstos son la materia prima para las políticas públicas ineficaces que reinan en la región. Otra dimensión vital para crear políticas preventivas debe ser el empoderamiento y la participación de los hinchas en el diseño, la planificación y ejecución de las mismas. Los hinchas son una parte de la sociedad civil movilizada y organizada, encauzar esas cualidades en pos de una construcción de seguridad deportiva integral puede ser una estrategia tan novedosa como fructífera. 
Finalmente, nos interesa que este trabajo aliente nuevos horizontes de análisis, por ello es que quedamos expectantes de interrogantes vinculados a nuestro tema que no han podido ser saldados aquí. Sobre los orígenes de dicho fenómeno resulta imprescindible avanzar en una acumulación, sistematización y análisis de datos tendientes a responder ¿Porqué "el fútbol" en general y las organizaciones de espectadores en particular fueron fundamentales como "espacios de fuga" para el agrupamiento y la acción colectiva en contextos de libertades coartadas? Además debemos profundizar en las continuidades y discontinuidades organizativas de cada caso buscando responder ¿A qué se debe la vía burocrática-institucional alcanzada por las torcidas organizadas? ¿Por qué en las hinchadas argentinas la institucionalización no aparece en el horizonte de lo posible entre sus protagonistas? y ¿Cómo se relacionan las especificidades de cada caso con sus notorias vinculaciones con el mundo de la violencia y la ilegalidad? Otro interrogante que emerge a raíz del último mundial en Brasil 2014 es los referidos a las visibles vinculaciones entre hinchadas y torcidas organizadas ¿Qué tipo de reciprocidades o intercambios se dan a partir de estos encuentros y lazos internacionales? ¿Se puede pensar en una cultura transnacional o regional de espectadores de fútbol organizados? En fin, los interrogantes abundan y no podía ser de otra manera para una temática que inquieta, desvela, apasiona y mantiene inalterable su intensa vigencia.

\section{REFERENCIAS}

ALABARCES, P. Crónicas del aguante.: Buenos Aires: Capital Intelectual, 2004.

ARCHETTI, E. Fútbol y ethos. Facultad Latinoamericana de Ciencias Sociales - FLACSO. Monografías e informes de investigación: Buenos Aires, 1985.

CANALE, V. S. Torcidas organizadas e seus jovens torcedores: diversidades e normativas do torcer. 2012. 121 f. Dissertação (Mestrado em Educação Física) - Curso de Educação Física, Faculdade de Educação Física, UNICAMP, Campinas, 2012.

CABRERA, N.. Etnografía, violencia y poder en la hinchada del Club Atlético Belgrano de Córdoba. In: REUNIÓN DE ANTROPOLOGÍA DEL MERCOSUR, 10., 2013, Córdoba. Anais...Córdoba: Universidad Nacional de Córdoba, 2013a.

CABRERA, N. Cuerpo, género y clase en las prácticas violentas de una hinchada de fútbol. Revista Questión, La Plata, v. 1, n. 37, p. 239-253, 2013b. Disponível em: http://perio.unlp.edu.ar/ojs/index. php/question/article/viewFile/1756/1481. Acesso em: 15 mai. 2014.

CAVAROZZI, M. Autoritarismo y democracia (1955-1996). Buenos Aires: Ariel, 2006.

DA MATTA, R. Carnavais, malandros e heróis: para uma sociologia do dilema brasileiro. Rio de Janeiro: Zahar, 1979.

GARRIGA ZUCAL, J. Haciendo amigos a las piñas: violencia y redes sociales de una hinchada de futbol. Buenos Aires: Prometeo, 2005.

GEERTZ, C. La interpretación de las culturas. Barcelona: Gedisea, 1990.

HOLANDA, B. B. B. 0 clube como vontade e representação: 0 jornalismo esportivo e a formação de torcidas organizadas de futebol no Rio de Janeiro (1967-1988). 2009. 771 f. (Doutorado em História) Pontifícia Universidade do Rio de Janeiro, Rio de Janeiro, 2009.

MURAD, M. A violência e o futebol: dos estudos clássicos aos dias de hoje. Rio de Janeiro: Editora FGV, 2007.

TOLEDO, L. H. Torcidas organizadas de futebol. Campinas, SP: Autores Associados/ Anpocs, 1996. 
TOLEDO, L. H. Lógicas no futebol. São Paulo: Hucitec: Fapesp, 2002.

PALHARES, M. F. S.; SCHWARTZ, G. M.; TERUEL, A.P.; SANTIAGO, D. R. P.; TREVISAN, P. R. T. da C. Lazer, agressividade e violência: considerações sobre o comportamento das torcidas organizadas, Motriz, Rio Claro, v. 18, n. 1, p. 186-199, 2012.

PIMENTA, C. A. M. Torcidas organizadas de futebol: violência e auto-afirmação, aspectos da construção de novas relações sociais. Taubaté: Vogal, 1997.

ROMERO, A. Muerte en la cancha (1958- 1985). Ediciones Nueva América: Buenos Aires, 1986.

SANTOS, T. C. Dos espetáculos de massa às torcidas organizadas: paixão, rito e magia no futebol. São Paulo: Annablume, 2004.

WEBER, M. Economía y sociedad: esbozo de sociología comprensiva. Fondo de Cultura Económica: México, 1994. 
Endereço para correspondência

Marcelo Fadori Soares Palhares

Endereço Postal: Av 24-A, 1515 - sala 26 - Bairro: Bela Vista - Rio Claro, SP - Brasil

Auxílio financeiro: CAPES e CONICET 